\title{
THE ART OF AMBIGUITY: \\ A CONVERSATION WITH ZEN MASTER HISAMATSU
}

JEROME S. BRUNER

\author{
Harvard University
}

The interview had been arranged. There had been the polite exchange of letters with a third party. The Zen Master arrived with interpreter shortly after the appointed four o' clock. He is an exquisite man, in his fiftie; perhaps, dressed in a slender robe of brown and black, over which was a silk over-jacket lined with delicate, long white fur.

There was formal bowing. I beckoned the Zen Master and his interpreter to sit on the couch. He rose to look at pictures, and he stopped before a woodcut by Kathe Kollwitz. A Cherokee mask caught his eye. I took it from the wall to show him. He was reminded of the Japanese Theatre. Of a drawing by Elizabeth Westfeldt he said, "It has much natural spontaneity." Whereupon he presented a calling card in the form of a drawing and a box of chocolates purchased in Harvard Square.

Hisamatsu is a composed man. He smiles easily, never grins. The interpreter does not smile, only grins.

Z.M. You are in the field of Social Relations in Social Psychology? Is that not right?

Dr. B. It is a label invented by administrators.

Z.M. (Laughing) Well, then, what is it that does concern you?

Dr. B. I'm preoccupied with how it is that we know, know anything, ourselves included. I've been interested in Zen Buddhism, what little of it I've read, in the emphasis that it puts upon the dangers of labelling experience, a means whereby we destroy its freshness. You seem to be inviting people to look at things with a fresh eye, without ready categories.

Z.M. What would you take as an example?

Dr. B. (I take from the desk a copy of Hans Heinrich's The Glutton's Paradise). This book, for example, if I simply call it a book I lose sight of the fact that it is a gift that combined admiration and hostility, that it is much more than a book. You counsel that experience not be easy.

Z.M. The ultimate ambiguity, though, is not so much in describing things as in expressing self. What do you American psychologists make of the self? Or better, what makes it more difficult to describe self than things?

Dr. B. Psychology, it would seem, has practically nothing to say today about the knowing of self. What makes difficult the perceptual description of things is the myriad ways in which things relate to self. It is no easier to resolve when we grasp the fact that the self is a cast of characters and that a given thing has a different meaning to each member of this cast.

Z.M. But the deeper self, what does psychology say about that? Does it for example make a distinction between the self and an object? What is it you mean when you say that you experience yourself? What is the thing that is purest about your experience of self? 
Dr. B. I expect the thing that I or anybody finds purest in the experience of self is the sense of love. But here too there is an ambiguity. For at the very time that the sense of love vivifies the experience of self, it also seems to lead to a loss of the self. In loving my children I lose myself in them and their concerns. Yet this sense of involvement is one of the most vivid features of my experience of myself. In loving a woman, love there is a fusing of self with another one in which one's sense of identity is somewhat lost. Yet again, retrospectively, the experience is one of the most vivid experiences of selfness.

Z.M. How can you lose yourself? What do you lose, and who loses it? Is it not that you are giving yourself and losing it in others and losing it in the things that you do?

I then asked the Zen Master whether he would like some tea or would he prefer whiskey. He assured me he was a teetotaler. I asked him why. He countered by asking, "Why do you drink alcohol 8 " I confessed that it gave me great pleasure and a sense of release.

Z.M. Yes, I can understand that, alcohol excites me but does not compose me. Tea which is a deep part of Zen allows me to be alert without exciting me and keeps me from being drowsy.

I then served the tea and offered him some candy from his package. He was reluctant to take it and explained as follows.

Z.M. In our country the giver cannot take the gift before the person for whom the gift was intended has had it.

Dr. B. But you must take one and I shall enjoy mine the more .... One hears today that there are many barriers that prevent Americans from developing a sense of self. We speak of Americans as having trouble with a sense of their identity, of identity being determined by one's relations with others. Have you some observations on this?

Z.M. But Americans too have True Self and this is at a deeper level than identity. I do not see this as a deep problem. Tell me, what do psychoanalysts mean by spontaneity?

Dr. B. I think what is meant is that one can express impulses, but there is an antinomy here. If one expresses impulses without some sense of what it will do to one's relationships with others one risks becoming isolated. The creative thing about spontaneity is being able to express impulses in such a way that one also enriches one's relationships with others.

Z.M. Ah yes, I see. This is natural spontaneity. But there is also a higher spontaneity, true spontaneity. It is above natural spontaneity. It is rational spontaneity. It is much like the Kantian autonomy of reason and is higher than expressing one's natural impulses.

Dr. B. How then does one deal with one's impulses in this higher form of spontaneity? Do they become reasonable or rational too? What happens to them?

Z.M. Rational spontaneity is the second stage. There is one higher than that in Zen.

Dr. B. I should like to know more about rational spontaneity, for it must indeed be a fragile thing when impulses go out of control and disrupt it. How does one compose the conflict between impulse and rationality?

Z.M. Rational must overcome natural spontaneity.

Dr. B. What does "must" mean when you say that?

Z.M. (Laughing) I should have said should overcome natural spontaneity.

Dr. B. I suppose you are right. If rational spontaneity does not in some measure over- 
come natural spontaneity, we do have a way of dealing with people - we put them in jail or something equally drastic.

Z.M. What I do not understand is how psychoanalysis can emphasize only natural spontaneity and hope to get people to deal with the world. How does it come about that there is such heavy emphasis on natural spontaneity and so little upon rational spontaneity?

Dr. B. I do not think the emphasis is exclusively in that direction. Surely you are overlooking the moralist in Freud. Indeed, Anna Freud once began an address here at Harvard by commenting that if a three year old had the muscular coordination and the weapons, he would likely commit every crime in the code book while walking between Central Square and Harvard Square. But the initial emphasis on natural spontaneity is understandable enough. Consider the historical conditions of the intellectual world of the Ninteenth Centruy against which psychoanalysis was rebelling. Freud was, after all, redressing the balance. There seems always to be a cycle in the West between the romantic ideal of impulse and the classic ideal of rationality.

Z.M. But is it not true that among the intelligentsia one finds the major conflicts within thought and that these conflicts cannot be resolved by natural spontaneity. To be sure there are some problems that are overcome by natural spontaneity but the problems of our age exist as conflicts within rational spontaneity not between rational spontaneity and natural spontaneity. "What should we do?" is a problem within rational spontaneity. The conflict, the decision as to what to do must be an act of choice based on reason if it is to deal with the issues at hand. One must elevate rationality.

Dr. B. Has the Zen Master read much in Freud?

Z.M. I do not believe that rational conflict can be handled by psychoanalysis.

Dr. B. Freud, too, believed that natural spontaneity would not handle all the problems and it was for that reason that he placed such emphasis later in life upon the functioning of the ego and no longer considered it a powerless rider on a surging horse.

Z.M. Does the maturing ego for Freud mean the development of rational spontaneity?

Dr. B. I'm not quite sure it is simply that. Freud also urged that in order to be rational you had also to know your own impulses. What of Zen? Does it hold that too?

Z.M. From the Zen point of view one goes from natural to rational spontaneity, and then from rational to Zen spontaneity. The latter occurs when one realizes that there are conflicts within the rational sphere which cannot be resolved with rational spontaneity.

Dr.B. Is that what is meant by satori?

Z.M. Satori means such a spontaneity where the conflicts have been disentangled. Satori is the ultimate spontaneity.

Dr. B. I am not sure I understand. Earlier you spoke of that picture there as having much natural spontaneity. Can you illustrate rational spontaneity or ultimate spontaneity in terms of works of art? There is a mobile I have been making. It is made up of many beautiful individual forms, natural forms, and $I$ thought that by joining them in a mobile one would be able to see them from many angles as they moved, almost as if they were in a natural medium of pure water. That was my rational intention. There were doubtless some natural impulses involved too. Is there not always a fusing of these - even in a bit of nonsense like this mobile?

Z.M. It is not that there is a composing of rational and natural spontaneity. Rather, you 
must pierce through, get beneath each until one reaches True Self. That is what True Self is. It consists of going down beneath (his hands move downward and then upward as if describing an explosion from below). This is True Self: going beneath spontaneity.

Dr. B. The imagery is beautiful, but I am not sure I understand.

Z.M. I went to a concert yesterday, the Boston Symphony, with music by Beethoven and Schubert and others. It was lovely music but it stayed within the limits of sound, within its own medium. It does not break into the bottom of the world of sound, does not break through it. Truly great music would be music which negated sound, the paradox of sound negating sound. That is deep music. One finds it is some oriental music where somehow one breaks through and goes deeper or beyond the rhythnuc forms. Such oriental music is not based upon rhythm or sound, but comes from beneath them, from some deeper source: from True Self.

Dr. B. What music do you mean?

Z.M. I mean, for one, the music of the Noh Plays.

Dr. B. I would like to play you one piece of music which I think to be deep and which lies midway between music and poetry. It is a record of Elizabeth Schwarzkopf singing Bach's Bist du bei Mir. I should like to hear your reactions to it.

(The record is played.)

Z.M. (Running his hands horizontally as if describing shallow ripples on water.) It is on the surface. It is not down under the surface.

Dr. B. But perhaps you must understand the idiom and style of this genre to appreciate whether it achieves the objective of going beneath sound, beneath music.

Z.M. No, I do not think this is so. There must be a deeper self that can appreciate and sense the achievement of going deeper, going to an expression of True Self. True Self would appreciate such music, would appreciate it without regard to idiom or style.

Dr. B. Perhaps you are proposing something more ambitious than Wagner's Allgemeinekunstwerk. You are proposing something that is beyond all idiom, beyond all formal disciplines that exist within art. Yet it is something different from Wagner's idea, I sense.

Z.M. It is not a general art work, but an "underneath art work" above all it must be "Nicht Etwas" (not a something). By being not something an art work of this kind can therefore be related to everything. It is like formless Self, Self without form. Therefore it can take on various forms, indeed every form.

Dr. B. Is it then potentiality of which you speak, this subterranean unversality in art?

Z.M. No, it is beyond potentiality. Potentiality inplies something not present. Formless being is present. It is present and continuing. It continues as an expression of formless Self. It implies an eternal now.

Dr. B. May I ask a rude question? How do you teach? I as a university professor give lectures or seminars, direct theses. What do you do?

Z.M. As now. This is how I teach. There is a joke in Japanese which says "If words are words they are not true." In Zen negation is not mere negation. "Not something" does not mean the negation of something, rather it means going underneath, going to a formlessness beneath a work of art. This formlessness finds various forms of expression, as in painting, in flower arranging, in ceramics. 
Dr. B. In science?

Z.M. If I become pure, if I become my True Self, I become more scientific. If I achieve this then my rational spontaneity will be capable of a more concentrated expression.

Dr. B. It has been said that Zen is anti-scientific. Is this true?

Z.M. The point that cannot be solved by science can be solved by Zen. Just as ordinary music does not go beneath music and great music does, so science to be more than ordinary science must go beneath itself. True Self expressing itself makes great science.

Dr. B. How then might I get knowledge of my True Self so that I may be a better scientist, or indeed a better artist? Is there some way in which this can be achieved short of sitting at the feet of a great Zen Master?

Z.M. True Self is common to all human beings. To reach it one need not have a Zien Master. (Laughing.) Yet it is interesting that various Americans have asked me this. You can get satori here in America, you know.

Dr. B. May I ask who is the most interesting American that you have talked to on your visit here ?

Z.M. One who is with True Self. ${ }^{\star}$

At this point the Zen Master rose with the apology that he had a dinner engagement. We had had close to three hours of conversation and he was as composed and as unfatigued as at the start. I became acutely aware that there is no gesture at the command of an American for returning the bow of a departing Japanese gentleman. As he was leaving I said to him:

Dr. B. Would you be good enough to explain to me a beautiful Japanese poetic image that I came upon in reading a book by Alan Watts. If you hold water in your hands and the moon is reflected in the water, it exists there. But if there is no water in your hands there will be no moon reflected, and if there is no moon it will not shine in the water. What does this mean?

Z.M. Perhaps I can tell you with another poetic image. "The bottom of the bucket which Chiyono carries has fallen off; the water does not remain, so neither is the moon reflected."

\section{COMMENTS ON DR. BRUNER'S PAPER}

My general intention in this interview was to be understood at the following points: there are natural spontaneity and rational spontaneity, but there is one more: Zen spontaneity or ultimate spontaneity. Psychology treats natural spontaneity, but rational spontaneity is of a different character. In human life there is, of course, natural spontaneity, and we can stand on that ground. We can, however, go over natural spontaneity as a rational human being and reach a higher standpoint, that of rational spontaneity. But this, too, is not the ultimate spontaneity. There is one more, of higher dimension, or one may say 'deeper.' There is a

\footnotetext{
« Editor comments: Z.M. said this smiling, it is quite sure, looking at Dr.B. Have Dr.B. noticed that it was pointing to him: Dr.B. with True Self within?
} 